\title{
Spinal Neurocysticercosis: A Rare Variant of a Common Parasitic Infection
}

\section{Neurocisticercose espinhal: uma variante rara de uma infecção parasitária comum}

\author{
Paulo Moacir Mesquita Filho ${ }^{1}$ Nério Dutra Azambuja Junior ${ }^{1}$ José Ricardo Vanzin ${ }^{1}$ \\ Rafael D'Agostini Annes ${ }^{1}$ Daniel Lima Varela ${ }^{2}$ Moisés Augusto de Araújo ${ }^{1}$ \\ Vanderson Rodrigo de Araújo ${ }^{1}$ Candice Ghelen Bregalda ${ }^{1}$ Timóteo Abrantes de Lacerda Almeida ${ }^{3}$ \\ ${ }^{1}$ Department of Neurosurgery, Passo Fundo City Hospital, Passo \\ Fundo, Rio Grande do Sul, Brazil \\ 2 Department of Neurology, Passo Fundo City Hospital, Passo Fundo, \\ Rio Grande do Sul, Brazil \\ ${ }^{3}$ Department of Neurosurgery, São Vicente de Paulo Hospital, Rio \\ Grande do Sul, Brazil

\begin{abstract}
Address for correspondence Paulo Moacir Mesquita Filho, MD, Department of Neurosurgery, Neurology and Neurosurgery Service, Passo Fundo City Hospital, Passo Fundo, Brazil, 640 Teixeira Soares Street, ZIP Code 99010-080, Passo Fundo, Brazil (e-mail: pmesquitafilho@hotmail.com).
\end{abstract}

Arq Bras Neurocir 2017;36:66-70.

\begin{abstract}
\section{Keywords}

- neurocysticercosis

- spine

- spinal neurocysticercosis

\section{Resumo}

\section{Palavras-chave}

- neurocisticercose

- coluna

- neurocisticercose espinhal

Neurocysticercosis is the most common parasitic infection affecting the central nervous system, usually involving the brain parenchyma, intracranial subarachnoid space, or ventricular system. In rare cases, there is involvement of the spine (vertebral, epidural, subdural, arachnoid, or intramedullary). Even in endemic regions, this variant is rare, with an incidence below $5 \%$ of all patients. The diagnosis is made based on the symptoms, which can be very unspecific, imaging and CSF analysis, with biopsy as a possibility. Treatment is usually curative, but important deficits can develop, due to compression of the spinal cord or nerve roots, arachnoiditis, or meningitis. We present the case of a patient who developed this entity, with poor clinical scenario, and review the literature on the topic.

Neurocisticercose é a infecção parasitária mais comum afetando o sistema nervoso central, geralmente envolvendo o parênquima cerebral, espaço subaracnóide intracraniano ou sistema ventricular. Em raros casos, há envolvimento da coluna vertebral, espaços epidural e subdural, aracnoide, ou intramedular. Mesmo em áreas endêmicas, esta variante é rara, com incidência abaixo de $5 \%$ entre todos os pacientes. 0 diagnóstico é feito com base nos sintomas, que podem ser bastante inespecíficos, neuroimagem e análise do líquor, sendo a biópsia uma possibilidade. $\mathrm{O}$ tratamento geralmente é curativo, porém importantes déficits podem se desenvolver, devido à compressão da medula espinhal ou raízes nervosas, aracnoidite ou meningite. Relatamos o caso de um paciente que desenvolveu esta entidade, com sintomatologia escassa, e revisamos a literatura sobre este tópico.
\end{abstract}

received

September 15, 2015 accepted

November 25, 2015

published online

February 15, 2016
Dol http://dx.doi.org/

10.1055/s-0035-1571268. ISSN 0103-5355.
Copyright (c) 2017 by Thieme Revinter

Publicações Ltda, Rio de Janeiro, Brazil
License terms

$(1) \ominus \circledast$ 


\section{Introduction}

Human cysticercosis is a systemic infestation caused by Cysticercus cellulosae, the larval form of Taenia solium. Neurocysticercosis (NCC) is the most common parasitic infection affecting the central nervous system, ${ }^{1-4}$ usually involving the brain parenchyma, intracranial subarachnoid space or ventricular system. In many cases, the infection is selflimited and diagnosed as an incidental finding. The spinal variant, however, even in endemic regions is rare, with an incidence of around 1 to $5 \%^{1,2,4}$ Less than 200 cases have been reported so far. ${ }^{1,3}$

We report the case of a patient who developed this rare form of NCC, with unusual clinical findings, and review the literature about this entity.

\section{Case Report}

We present the case of a 57-yearold woman, presenting with a 3-week course of headache and posterior neck pain, initially relieved with analgesics, but that have worsened recently. She developed episodes of disorientation and intermittent fever during the evening. The patient also complained about low back pain, irradiated to the right inferior limb. There was no previous history of chronic pathologies, neither cancer nor inflammatory conditions. The physical examination showed only a mild nuchal stiffness, aside from intermittent fever.

The initial CSF evaluation evidenced mild elevation in the leucocytes (11 cells $/ \mu \mathrm{L})$, with $100 \%$ of mononuclear cells, extremely low glucose levels ( $2 \mathrm{mg} / \mathrm{dL}$ ), and elevated protein levels $(100 \mathrm{mg} / \mathrm{dL}$ ). The CSF culture was negative. The serum examination was uneventful, and the inflammatory tests were negative. Thoracic X-rays were also normal.
We performed a Magnetic Resonance Imaging (MRI) of the brain, which was normal, and of the entire spinal canal, evidencing multiple intradural, extra-spinal cystic lesions from C4-C7 displacing the spine posteriorly, with a weak impregnation by the gadolinium. There were also lesions with the same features at the levels of T12 to L1 and from L1 to S2, surrounding the neural roots (-Fig. 1-2).

Empirically, she received treatment for tuberculosis during four weeks, with partial remission of the symptoms. We repeated the neuroimaging of the spine after 30 days of treatment, evidencing that there was no improvement. The new CSF examination revealed persistence of low glucose levels and high protein levels (Cells: 11 cells/ $\mu \mathrm{L}$; monocytes: 95\%; neutrophils: 5\%; Glucose: $5 \mathrm{mg} / \mathrm{dL}$; Proteins: $60 \mathrm{mg} / \mathrm{dL}$; Lactate: $52 \mathrm{mg} / \mathrm{dL}$ ), with persistent negative culture. Serum examination evidenced increased inflammatory markers. Thus, we decided to perform a biopsy in one of the lumbar lesions. The biopsy was compatible with spinal neurocysticercosis. The patient received therapy with albendazol plus steroids and is currently recovering very well (-Fig. $\mathbf{3}$ ).

\section{Discussion}

The first case of NCC involving humans was described by Paranoli Rumi in $1550{ }^{1,3}$ whereas Rockitansky, in 1856 , made the first reference of intraspinal cysticercosis. Cysticercosis is widely endemic in Brazil, Peru, Mexico, Tropical Africa, Korea, and India. ${ }^{2,3,5}$ As indicated by autopsy findings, the incidence in these regions can be as high as $4 \%$ of the general population; in Brazil, recent reports suggest that $7.3 \%$ of hospital admissions were related to NCC. ${ }^{6}$ In the United States, the first case of NCC was reported by Walter Dandy in 1927, and there have been more frequent reports of
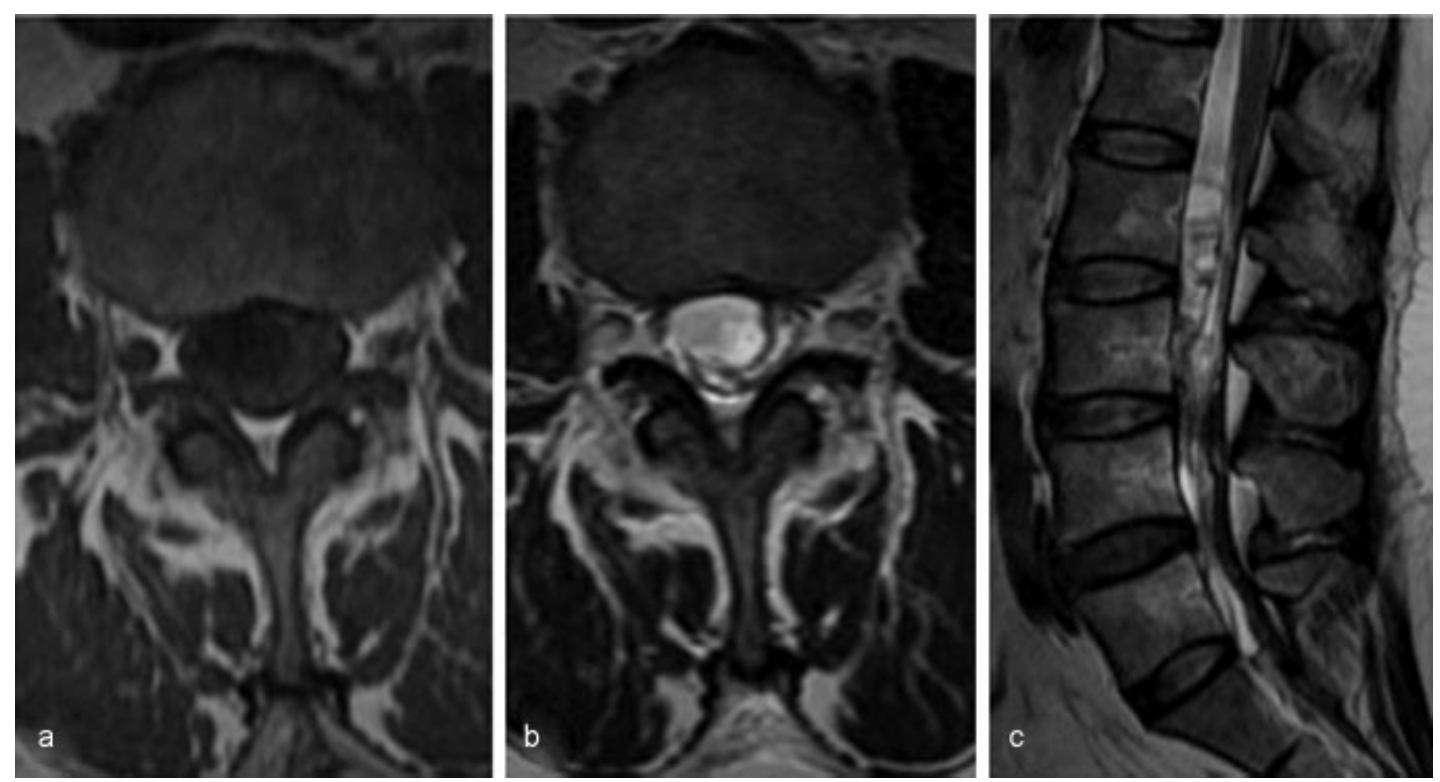

Fig. 1 (a) Axial T1-weighted MRI of the lumbar spine, showing an intradural hypointense mass, distorting the contents of the spinal canal. (b) Axial T2-weighted MRI of the lumbar spine, showing an intradural hyperintense mass and arachnoiditis, with posterior dislocation of the cauda equina. (c) Coronal T2-weighted MRI of the lumbar spine, showing an intradural heterogeneous mass and arachnoiditis, with extensive dislocation of the cauda equina from L2 to L5. 

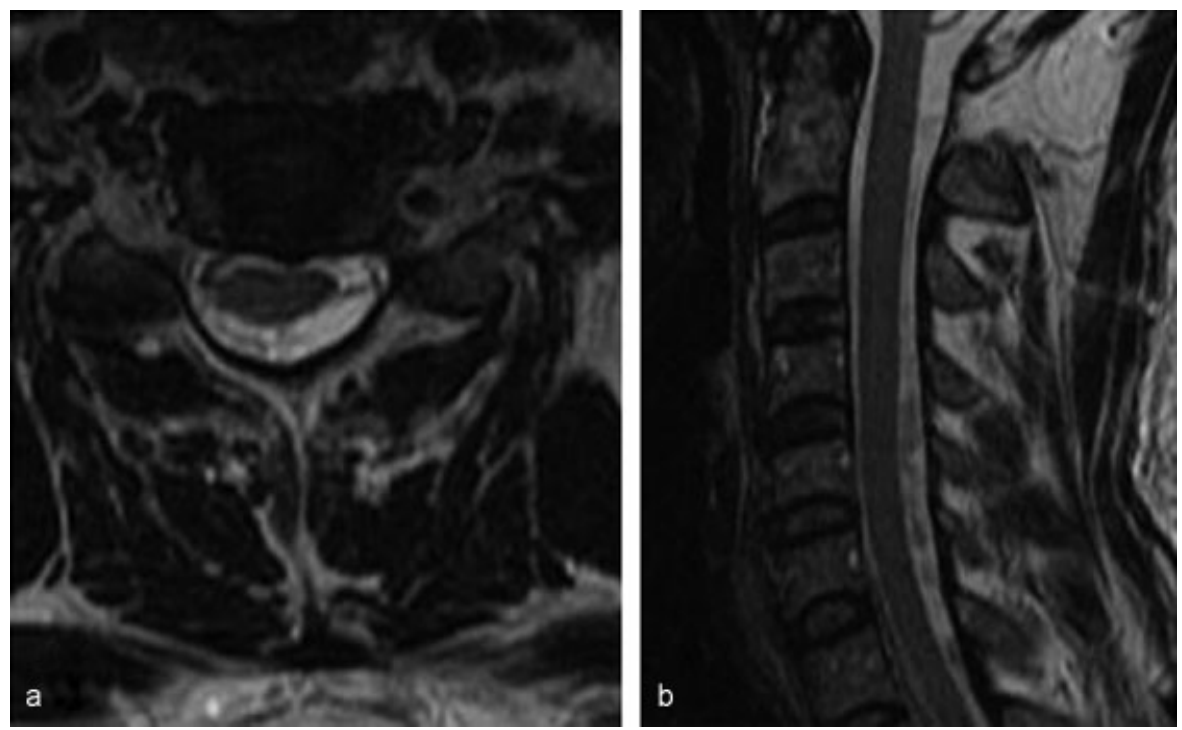

Fig. 2 (a) Axial T2-weighted MRI of the cervical spine, showing an intradural heterogeneous signal intensity, compatible with arachnoiditis, as well as mild dislocation of the spinal cord from the midline. (b) Coronal T2-weighted MRI of the cervical spine, showing an intradural heterogeneous signal intensity, compatible with arachnoiditis.

the disease in the Southwestern United States in recent years, especially among recent immigrants. ${ }^{3,5}$

Human cysticercosis is a systemic infestation caused by Cysticercus cellulosae, the larval form of Taenia solium. ${ }^{1}$ The parasite's life cycle is well known, as pigs are the intermediate host and humans are the definitive (or occasionally intermediate) host. NCC typically results from the ingestion of cysticercal eggs in food contaminated by human or porcine feces. During digestion, gastric acid releases the larvae from the eggs, which penetrate the intestinal mucosa and follow to the bloodstream, where they primarily deposit in muscles, brain, and the eyes. ${ }^{3,5}$ Dissemination in the central nervous system (CNS) occurs through small capillaries into the parenchyma or through the choroid plexus into the ventricles, eventually leading to the subarachnoid space. ${ }^{3}$

Spinal neurocysticercosis (SNCC) can be classified according to the anatomical location of the cysticercus in the spine: extra-spinal (vertebral) or intra-spinal (epidural, subdural, arachnoid, or intramedullary). ${ }^{2}$ Among these, the most common location of SNNC is the subarachnoid space, in $80 \%$ of all cases. ${ }^{2,7}$ The intramedullary type is quite rare, accounting for the remaining $20 \%$ of cases (only 53 cases have been reported until 2010). ${ }^{2}$ Inside the spinal cord, cysticercus usually distributes in the thoracic cord, with a few cases involving the cervical and the lumbar cord. ${ }^{2}$ The epidural occurrence of NCC in the spine is exceedingly rare. ${ }^{8}$
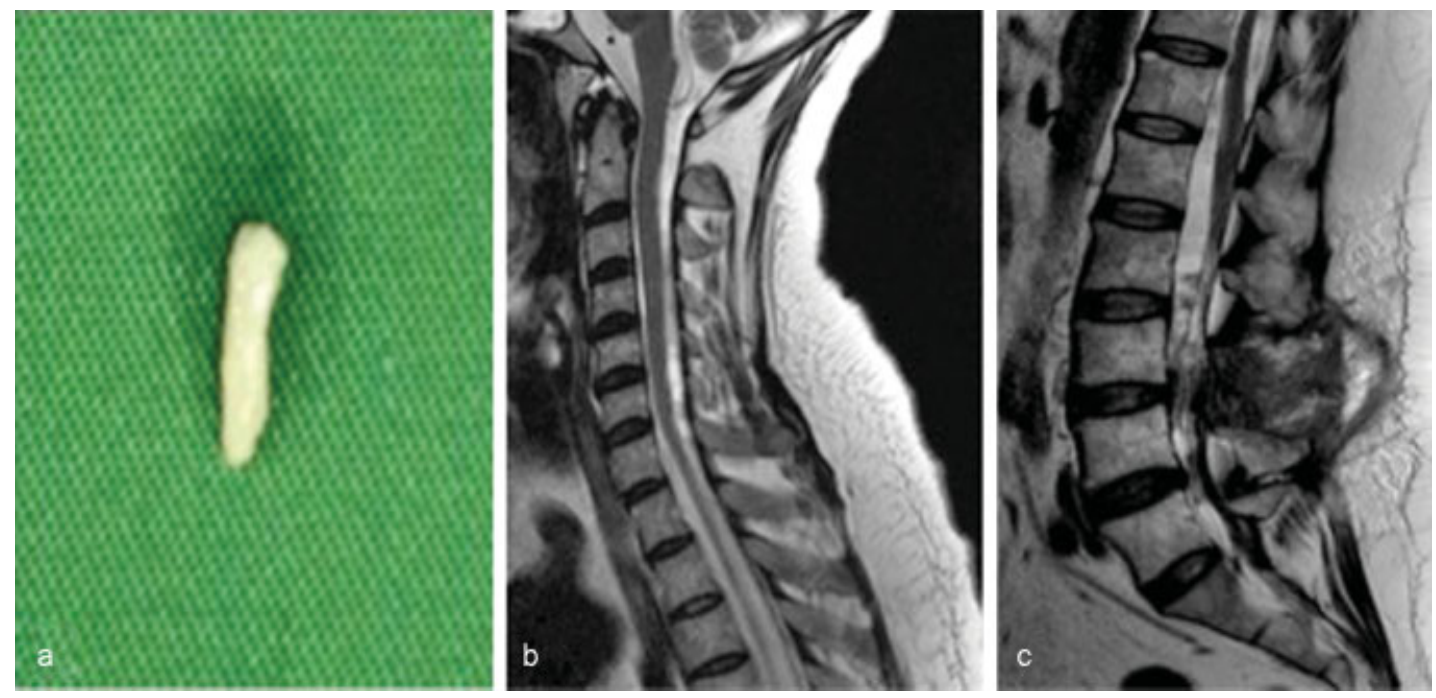

Fig. 3 (a) Intra-operative specimen. (b) Coronal T2-weighted MRI of the cervical spine, evidencing partial remission of the lesions in the cervical subarachnoid space. (c) Coronal T2-weighted MRI of the lumbar spine, evidencing partial remission of the lesions in the cervical subarachnoid space, and post-operative status. 
This distributional mode of cysticercus supports the hypothesis that intramedullary cysticercus comes from the blood circulation, because the thoracic cord has a lot more blood supply than other segments of the spinal cord. However, some authors believe that intra-medullary cysticerci could migrate to the spinal cord via the ventriculo-ependymal pathway. ${ }^{2}$ Regarding the intradural extra-medullary SNCC, one hypothesis given for Cysticercus larvae descending into this space, is the retrograde flow through valveless epidural venous plexus, which may conduct blood in any direction under the influence of intra-abdominal and intrathoracic pressure variations. ${ }^{1,7}$

Nevertheless, the location of a subarachnoid spinal cysticercal cyst is not necessarily fixed. Studies have demonstrated the migration of the cyst during myelographic procedures, similar to what happens in the ventricular compartments. Thus, the time between neuroimaging and excision should not be long, to ensure that the lesion will be within the planned surgical field. ${ }^{3}$

The reason that the incidence of the disease in the spinal canal is so low when compared with the cranial infection is not clear. Queiroz et al proposed that the CSF reflux at the cranio-vertebral junction can prevent the spinal dissemination by propelling the floating cysts back to intracranial space. ${ }^{1,3,8}$ Although the larval migration is prevented by CSF reflux, this portal remains the most important mode of entry for Cysticercus larvae to the spinal territory. 1,7

The clinical scenario varies accordingly to the region affected, as well as the size of the lesion, and, eventually, an inflammatory process due to the cysts degeneration. ${ }^{1,3}$ There might be myelopathy or radiculopathy due to mass effect, or arachnoiditis and meningitis, as was the case in our patient. ${ }^{1,3,5}$ Extra-medullary disease, especially in the lumbar region, tends to give rise relatively slow and insidious onset of symptoms, whereas an intramedullary lesion in cervical canal produces fast and early deterioration. ${ }^{1}$ Most patients experience a progressive worsening course, that can vary in duration from one week up to many years. ${ }^{2}$ Common clinical manifestations include pain, paraparesis, spasticity, bowel and bladder incontinence, and sexual dysfunction. $^{2}$

The diagnosis is based on the clinical course, imaging findings, CSF characteristics, and sometimes, biopsy. Since approximately $2 / 3$ cases of SNCC occur in presence of concomitant cranial involvement and more than $50 \%$ of patients with intramedullary SNCC have evidence of $T$. solium infection elsewhere, an entire neuro-axis evaluation should be considered. ${ }^{1,5,8}$ Nevertheless, isolated cases in the spine have already been reported. ${ }^{1,5}$

The MRI is the best imaging technique to access SNCC. As proposed by Ratnalkar et $\mathrm{al}^{9}{ }^{9}$ there are 4 different stages of the disease, each with different findings, as follows: (1) Vesicular stage - cystic hypointense lesions in T1 and hyperintense in T2 weighted images, without any surrounding edema; occasionally the scolex can be identified as a mural nodule within the cyst cavity on T1-weighted images. The scolex is isointense to spinal cord parenchyma on T1-weighted acquisitions and does not show on T2-weighted images because it becomes isointense to the surrounding cyst fluid ${ }^{5}$; (2) Colloidal vesicular stage - mild hyperintense in T1 and hyperintense in T2, usually with perilesional edema (inflammatory response to a dying parasite); (3) Granulonodular stage - thickening of the capsule and initial calcification; (4) Calcified nodular stage - dense calcified scolics and cysts, usually difficult to identify in MRI, usually appearing as calcifications in the CT scan., ${ }^{1,3}$ All these stages can occur simultaneously. ${ }^{1}$

The use of gadolinium-enhanced MR images usually distinguishes the type of subarachnoid involvement, with a rim enhancement of a discrete intradural-extra-medullary cyst and a homogeneously enhancing sheet-like arachnoiditis. ${ }^{5}$ Some associated findings, like syrinx or infectious syringomyelia are caused by a combination of the effects of arachnoiditis, inducing subarachnoid adhesions, parenchymal circulatory insufficiency, and spinal cord atrophy. ${ }^{5}$ Myelographic studies, like post-myelography CT may be useful for detecting small subarachnoid SNCC lesions, although bringing risks of arachnoidal scarring and obstruction of CSF pathways. $^{3}$ In the case of our patient, the lesions exhibit the characteristics of the vesicular stage, as well as some subarachnoid adhesions.

The CSF findings often show increased protein levels, a low (even undetectable) or normal glucose, moderate lymphocytic pleocytosis, and eosinophilia. ${ }^{2,4}$ Cytologic examination may demonstrate high variability and atypia similar to central nervous system lymphoma. ${ }^{4}$ Cysticercal antibodies found in CSF by ELISA have a high sensitivity (87\%) and specificity (97\%), as opposed to sensitivity of $50 \%$ and specificity of $70 \%$ for serum serological studies, being a mainstay in the diagnosis. ${ }^{1,2,10}$ In our patient, the CSF was compatible with an infectious process, initially thought to be tuberculosis.

Sometimes, excision and histopathological examination remains the only definitive method of confirming the diagnosis. The typical histopathological findings of NCC, are the presence of dead or active translucent cysts with eosinophilic lining. ${ }^{1}$ The cyst is surrounded by a collagenous capsule that corresponds to the parasite itself. In the form known as cysticerci, an encystment of cysticercus larvae is seen. It is comprised by the tegmentum, the outer layer, covered by fine hairlike projections. Initially the cyst wall contains numerous ellipsoid vesicles and an inner loose fibrillated matrix made up of a network of canaliculi, representing the excretory system of the parasite, along with fascicles of muscle from the parasite, nucleated cells, scattered calcareous corpuscles, and occasional foci of calcification. The cyst's fluid is clear and there is an invagination in its wall corresponding to the scolex of the parasite. The cysts are usually surrounded by clear fluid and chronic inflammatory cells (neutrophils, eosinophils and giant cells), which is mild while the cyst wall remains intact and the organism is alive, but intense after the parasite dies. ${ }^{5}$ Calcified cysts can be seen in late and inactive stages. The meningeal thickening and signs of arachnoiditis are also common. ${ }^{1}$ Also, clusters of subarachnoid cysts can appear, and are referred to as "cysticercosis racemosus." 5 
The differential diagnosis should include hydatid cysts, tuberculosis, simple/complex arachnoid cysts, dermoid cysts, sarcoidosis, or subarachnoid neoplasm (primary or metastatic). ${ }^{1,5}$

Mohanty et a ${ }^{11}$ state that SNCC represents a focal manifestation of a systemic disease, thus recommending medical therapy in all patients. Usually, the treatment is based on the use of albendazole or praziquantel, the former having a superior penetration in the CSF. ${ }^{1,2}$ Albendazole is used at doses of $15 \mathrm{mg} / \mathrm{kg} /$ day for one week, up to a maximal dose of $800 \mathrm{mg} /$ day. ${ }^{12,13}$ Albendazole has higher parasiticidal effect than praziquantel. ${ }^{14}$ Praziquantel is most often used at doses of $50 \mathrm{mg} / \mathrm{kg} /$ day for 15 days, or even as a single-day regimen (25-30 $\mathrm{mg} / \mathrm{kg}$ at 2-hour intervals). ${ }^{15}$ Serum concentrations of praziquantel decrease when steroids are also used. ${ }^{16}$ Cysticidal drug therapy has been criticized by some clinicians because treatment associated parasite death leads to an acute, severe inflammatory reaction in the surrounding brain tissue, increasing intracranial hypertension and potentially leading to the death of the patient. ${ }^{17}$ Simultaneous administration of corticosteroids ameliorates the secondary effects of headache and vomiting that may occur during cysticidal drug therapy, which are associated to the destruction of parasites within the brain and spinal-cord and are reliable indicators of drug efficacy. ${ }^{18}$

Close and frequent neurological assessment is very important due to the possibility of acute neurological deterioration from the inflammatory response as the parasites die. ${ }^{1,19}$ If this happens, the neurosurgical team should consider surgical decompression of the spinal canal. The other indications for surgical treatment are severe and progressive symptoms and failure of medical management. ${ }^{1}$ Alsina et al, evaluating six cases of SNCC, suggested that medical treatment only appears to be a less viable option, due to the progressive neurological deficits of their patients. ${ }^{3}$ Other authors advise that surgery is the procedure of choice only when diagnosis is in doubt, otherwise, medical treatment has its advantages. ${ }^{2}$

The outcomes in patients with SNCC are thought to be related to the location (intramedullary or extra-medullary; cauda equine, or spinal cord levels), severity of inflammation (arachnoid scarring or parenchymal injury), and chronicity of symptoms/time to treatment. ${ }^{3}$

\section{Conclusion}

SNCC is very rare compared with intracranial neurocysticercosis, which has a relatively high incidence in endemic regions of the world. Nevertheless, it should always be considered in the differential diagnosis in patients who present with multiple lesions in the spinal canal, as well as in those who have CSF diagnosis of an underlying infection.

\section{References}

1 Gupta S, Singh PK, Gupta B, Singh V, Azam A. Isolated primary intradural extramedullary spinal neurocysticercosis: a case report and review of literature. Acta Neurol Taiwan 2009;18(3): 187-192

2 Qi B, Ge P, Yang H, Bi C, Li Y. Spinal intramedullary cysticercosis: a case report and literature review. Int J Med Sci 2011;8(5): 420-423

3 Alsina GA, Johnson JP, McBride DQ, Rhoten PRL, Mehringer CM, Stokes JK. Spinal neurocysticercosis. Neurosurg Focus 12(6). Article 2002;12(6):e8

4 Torabi AM, Quiceno M, Mendelsohn DB, Powell CM. Multilevel intramedullary spinal neurocysticercosis with eosinophilic meningitis. Arch Neurol 2004;61(5):770-772

5 Leite CC, Jinkins JR, Escobar BE, et al. MR imaging of intramedullary and intradural-extramedullary spinal cysticercosis. AJR Am J Roentgenol 1997;169(6):1713-1717

6 Takayanagui OM, Jardim E. Therapy for neurocysticercosis. Comparison between albendazole and praziquantel. Arch Neurol 1992;49(3):290-294

7 Mohapatra RN, Pattanaik JK, Satpathy SK, Joshi S. Isolated and silent spinal neurocysticercosis associated with pseudotumor cerebri. Indian J Ophthalmol 2008;56(3):249-251

8 De Souza Queiroz L, Filho AP, Callegaro D, De Faria LL. Intramedullary cysticercosis. Case report, literature review and comments on pathogenesis. J Neurol Sci 1975;26(1): 61-70

9 Rahalkar MD, Shetty DD, Kelkar AB, Kelkar AA, Kinare AS, Ambardekar ST. The many faces of cysticercosis. Clin Radiol 2000; 55(9):668-674

10 Rosas N, Sotelo J, Nieto D. ELISA in the diagnosis of neurocysticercosis. Arch Neurol 1986;43(4):353-356

11 Mohanty A, Venkatrama SK, Das S, Das BS, Rao BR, Vasudev MK. Spinal intramedullary cysticercosis. Neurosurgery 1997;40(1): 82-87

12 Sotelo J, Penagos P, Escobedo F, Del Brutto OH. Short course of albendazole therapy for neurocysticercosis. Arch Neurol 1988; 45(10):1130-1133

13 Garcia HH, Gilman RH, Horton J, et al; Cysticercosis Working Group in Peru. Albendazole therapy for neurocysticercosis: a prospective double-blind trial comparing 7 versus 14 days of treatment. Neurology 1997;48(5):1421-1427

14 Sotelo J, del Brutto OH, Penagos P, et al. Comparison of therapeutic regimen of anticysticercal drugs for parenchymal brain cysticercosis. J Neurol 1990;237(2):69-72

15 Bittencourt PR, Gracia CM, Gorz AM, Mazer S, Oliveira TV. Highdose praziquantel for neurocysticercosis: efficacy and tolerability. Eur Neurol 1990;30(4):229-234

16 Vazquez ML, Jung H, Sotelo J. Plasma levels of praziquantel decrease when dexamethasone is given simultaneously. Neurology 1987; 37(9):1561-1562

17 Kramer LD. Medical treatment of cysticercosis-ineffective. Arch Neurol 1995;52(1):101-102

18 Del Brutto OH, Sotelo J, Roman GC. Therapy for neurocysticercosis: a reappraisal. Clin Infect Dis 1993;17(4):730-735

19 Corral I, Quereda C, Moreno A, et al. Intramedullary cysticercosis cured with drug treatment. A case report. Spine 1996;21(19): 2284-2287 